\title{
Home and away: why consumers shy away from reporting negative experiences in the peer to peer realms
}

\begin{abstract}
Consumers of the collaborative platforms such as Airbnb assess their overall experiences not only from their perceptions of its quality, but also from the perceptions of home that they bring with them. This study investigates how customers use their construct of 'home' in perceiving their experience in peer-to-peer rented accommodation, as opposed to traditional hotels, that could lead to bias in their reviews. The literature has paid considerable attention to people's perceptions of destinations, but almost none to their perceptions of 'home' and its complexities whilst visiting a destination. This paper examines relationships between the concepts of 'home' or 'here' represented in peer to peer accommodation and the construct of 'away' or 'there' represented in traditional hotels. The literature dealing with concepts of 'here', 'there', closest to the notions of home and away, is reviewed in an attempt to understand whether the notion of home shapes the experience and affects the reporting behaviour of consumers using peer to peer accommodation.
\end{abstract}

This paper uses mixed methods to determine the existence of bias in reporting behaviour then explores its underlying motivations. Key findings indicate that there is a consistent review gap between institutional actors and peer to peer actors. Also, consumers of peer-to-peer accommodation prefer not to engage in negative reporting if a bond with the host is developed. Moreover, their perception of home shapes their relationship with the host and leads to reporting bias. This paper provides clear theoretical insights to advance our knowledge about the underlying motives behind reporting behaviour of negative experiences. Furthermore, it offers practical implications for both institutional and peer-to-peer contexts.

Keywords: reporting bias; online reviews; peer-to-peer; Airbnb; home and away; Destination; here and there; Space and place; social distance.

\section{Introduction}

Despite evidence in the marketing literature that consumers weigh negative reviews more heavily than positive ones (Yan \& Jian, 2018), in most reputation systems, reviews are overly positive and suffer from a degree of non-response bias (Fradkin et al., 2015; Resnick et al., 2006). Reputation systems serve as a new kind of digital institutions, helping to foster trust and loyalty in online markets (Caruana \& Ewing, 2010). Their value is however at risk when online feedback is affected by reporting biases (non-reporting of negative experiences). The accuracy of reputation is even more questionable within transactions associated with the 
"sharing economy" where uncertainty, asymmetrical information and risk are high. Within such environment, average reviews are unrealistically high (Ert et al., 2016). It follows that where accurate reputation systems are more needed, biases are even more severe. In a study conducted by Zervas et al. (2015) on over 600,000 Airbnb properties around the world, it was evident that $95 \%$ of these properties enjoyed a consumer average rating of $4.5-5$ stars. This was compared to hotels rated on TripAdvisor where the average rating was much lower reaching 3.5.

This study explores the bias in consumer reviews for peer-to-peer rented accommodation and how the construct of home, 'here', affects feelings towards the host. The notion of home is used here because this type of accommodation is someone else's home which can be experienced based on the consumer's frame of reference being their actual home. On the other hand, traditional hotels in this study can be associated with the construct 'away' due to being in a business-like environment where interactions with the hosts are low compared to a peer-to peer context. Reviews for traditional hotels often reflect less bias due to the perceived distance from the host. The type of reporting bias the current study focuses on is the nonreporting of negative experiences in the case of peer-to-peer accommodation.

Furthermore, this study aims to understand whether the home construct reduces the social distance and lead to negative reporting bias, i.e., consumers less willing to report negative experiences. According to Liberman et al. (2007) there are various dimensions of psychological distance, temporal, spatial, social, and hypothetical. In this paper we focus on social distance. When the interaction is institutional, e.g., a receptionist at the hotel counter, the social distance is high due to limited interactions between the parties. Conversely, when the interaction is peer-to-peer, social distance is lower and there is a rapport between the actors enabled by a home like environment (Priporas et al., 2017).

Our argument is that social distance between the actors affects the way in which consumers interpret the experience of stay. In particular, we argue that consumers' home construct 'here', used in shaping their experience, reduces the social distance in a peer-to-peer business model, in which the consumer and the provider interact more directly and develop a balanced (i.e., same level) relationship. Therefore, in case of a negative experience, we expect the customers' willingness to report it will be lower. This is due to the empathetic appraisal of their experience.

Conversely, in traditional business models the consumer and the service provider interact in an institutional setting. In these situations, consumers appraise service experiences in a 
business-like fashion, with higher social distance, reducing in turn reporting biases. Furthermore, the construct 'there' adds to the distance and reduces the empathetic appraisal of the experience.

The study poses the question of how our own homes, acting as frames of reference, affect our travelling experiences and whether this leads to closer relationships with the host resulting in the lack of reporting of negative experiences. Very little is known about the construct "here" that accompanies the traveller, or how it may manifest itself in constructing the destination. The current study addresses this gap in knowledge by looking into tourist's construct of home, 'here', and how it is used to interpret their destination and shape their experience in the context of peer-to-peer accommodation. The understanding of the consumer's experience based on how their frame of reference 'here' or 'home', affects their evaluation of it and lead to reporting bias is significant and leads to important theoretical and practical implications. Not only that this understanding will fill the gap in the literature about the role of home in interpreting and shaping a traveller's experience, it also helps practitioners understand how their products are evaluated through online reviews. Similarly, it will shed light on hosts' provision and promotion of their products on social platforms such as Airbnb. Therefore, the study is important for product development and online marketing and management.

\subsection{The issue of reporting biases among reviews' platforms}

Several scholars have highlighted the existence of a consistent positivity bias among online reviews platforms (Fradkin, Grewal, \& Holtz, 2018; Resnick, Zeckhauser, Swanson, \& Lockwood, 2006), and this happens both among product websites (e.g. Amazon) (Hu, Pavlou, $\&$ Zhang, 2009) and the tourism ones such as Yelp (Jurafsky, 2014), or TripAdvisor (Feng, Xing, Gogar, \& Choi, 2012) characterising the so-called J-shaped distribution of reviews' ratings.

More recently, scholars pointed how this effect is even more present among the sharing economies platforms (Pera et al., 2019; Bridges \& Vásquez, 2018; Feng et al., 2012; Zervas et al., 2015). For instance, Zervas et al (2015) found how 95\% of Airbnb online reviews score 4.5 to 5 , meaning negative ratings on the platform are very rare (Cansoy \& Schor, 2016), and representing only $2 \%$ of the total (Bridges \& Vásquez; 2018).

The reasons behind this phenomenon have been focused on by an increasing number of marketing and tourism scholars (Pera et al., 2019; Bridges \& Vásquez, 2018), showing how, when specifically examining sharing economies settings (e.g. Airbnb), elements like human 
interaction between actors as well as fear of retaliation in the reviewing process play a critical role for this purpose. Moreover, according to Yannopoulou et al. (2013) another crucial element could be the different level of expectations between institutional customers and peerto-peer guests, the latter being more realistic and focused on the human interaction rather than on the service standards. Ikkala \& Lampinen (2015) found how Airbnb users enjoy the membership of this community even as an opportunity to enhance their social connections. However, other elements have been investigated by scholars. One of these is the reciprocity in the reviewing system of Airbnb, as found by Fradkin et al (2015) which can also contribute to the overall positive bias. Moreover, due to the lack of anonymity, reviews are less likely to be overtly negative (Sun, Youn, Wu, \& Kuntaraporn, 2006; Wang, 2010). In addition, since many users integrate their profiles across different social media platforms, this may affect their propensity to publicly share negative commentary as they may be reluctant to share such information on their private accounts. This also may have an impact on the positivity bias in the ratings and reviews system (Bridges \& Vásquez, 2018). Furthermore, part of the underrepresentation of negative reviews may also be ascribable to the peer-to-peer platform's practices (e.g. Airbnb), as it is not possible to know the actual number of received reviews as well as of filtered ones, but we can rely only on the published comments.

In this scenario, several elements may affect the reputation system of sharing economy platforms, and an accurate investigation on the actual drivers is still needed (Zervas, 2015). In order to dig into this topic, it is important to pay attention to actual consumer experiences and what affects their perception of those experiences (Han, Mankad, Gavierneni, \& Verma, 2016). In this vein, our study therefore aims to explore how the concepts of "home" and "away" may play a critical role affecting the reviewing process and, in turn, the positivity bias among peer-to-peer platforms.

\section{Conceptual framework}

\subsection{The notion of 'here' (home) and 'there' (away) as a way to influence the social distance between the host and the guest}

Social distance is theoretically defined as the closeness of individuals in a social exchange (Liberman, Trope \& Stephan, 2007). Liviatan et al. (2008) found that being closer to the target people produce higher-level representations and judgements of their actions. Moreover, there is well-supported evidence that feelings of closeness to a person promote allocation of resources to him or her (e.g., Nadler, 1999; Dovidio et al., 1997; Hoffman et al., 1996). However, White, MacDonnell and Dahl (2011) have expanded this by showing that having a human connection or sharing spaces is a key determinant of social distance. Within psychological distance, the construct of social distance reflects the level of closeness of individuals in a social exchange (Liberman, Trope \& Stephan 2007, 357) and particularly 
refers to the social proximity between parties (Darke et al., 2016; Stephan, Liberman, Trope 2010).

Construal level theory (CLT) proposes that psychological distance - the removal of events from direct experience in terms of time (when), space (where), social distance (who), or hypotheticality (whether) - influences how people perceive, represent and judge events (Liberman \& Trope, 2008; Trope \& Liberman, 2010).

Inspired by CLT, we propose that social distance plays a key role in how guests behave in their reviewing processes, after experiencing a negative stay, exploring how the role of feeling at "home" or "away" conceptualised in the CLT framework may affect their reviewing behaviour.

We found the literature on 'here' and 'there' the closest to the construct 'home and away' and therefore useful in exploring consumers' relationship with the host and consequently their reporting behaviour. The consumers' experience of travel may be considered a binary opposition between the destination and home, which functions as a reference-point (Rojek, 1997). These locations presently designated "here" and "there" are socially and personally constructed, as well as having a physical existence (Entrikin, 1991; Willis et al., 2017), and the relationship perceived between them during the process of touring is also socially constructed (Crouch et al., 2001; Rojek, 1997). The construct "here" is often the source of the preconceptions, feelings, attitudes and symbols that make up the tourist's construct "there" (Oakes, 2005; Crouch \& Desforges, 2003; Crouch et al., 2001), and the process of touring seems to involve an existential comparison and perhaps stock-taking of one's "here" and "there" constructs (Urry, 1990:12; Wang, 1999; Steiner \& Reisinger, 2006). Yet although much has been written about the symbolic gaze (e.g. Bruner, 1991; Urry, 1990; Urry \& Larsen, 2011; Baerenholdt et al., 2017) and the social construction of tourist destinations and attractions (Martin, 2010; Laing \& Crouch, 2009; Hennig, 2002; Crouch et al., 2001; Johns \& Clarke, 2001; Selwyn, 1996, Graburn, 1989; Bærenholdt et al., 2017), Willis et al. (2017) challenged the conventional notion of the tourist gaze. They posit that, through modern technology, consumers can disconnect from the destination and be virtually present at home 'to take part in the mundane rituals of everyday life'. This way, the business traveller is inclined to focus on what is missing from the destination and long to be present in the familiar and the routine of home (ibid: 49).

Besides being relative points in space, "here" and "there" also carry connotations of familiarity and otherness, influenced inter alia, by role, tradition and culture. Rather than 
exchanging one "here" for another (e.g. "wish you were here"), travellers take the familiar world with them into the unfamiliar (Willis et al., 2017). Meinecke (2015:20) comments: "individual values appear as universal to the man who pursues them. But they are never universal, for they always bring with them a clump of native soil from the national sphere, a sphere that no individual can completely leave behind" . "Here" is not just a spatial "clump of soil" but is rich with personal, social and ideological meaning, since "here" is where one dwells and where familiarity confers a sense of ownership (Crouch et al., 2001; Crouch, 2010). The values and norms of "here" are one's own property, and one's own properties, making "here" in many ways equivalent to self.

Both "here" and "there" define and are defined by roles, the "here" role set being especially associated with heritage and tradition. For instance, MacIntyre (2003: 560) comments: "I inherit from the past of my family, my city, my tribe, my nation, a variety of debts, inheritances, rightful expectations and obligations". These properties bind "here" intricately to one's concept of self, so that the "clump of native soil" influences everything the individual does whilst "there"; as MacIntyre (2003: 561) notes: "the individual's search for his or her good is generally and characteristically conducted within a context defined by those traditions of which the individual's life is a part." When individuals go abroad, to "there", not only do the traditions of "here" go with them, but "here" also provides the tools with which "there" is interpreted and understood: as Bruner (1991) and Suvantola (2017) assert the best way to discover the real is through one's symbolic system, therefore, it is important to explore the tourist's point of view.

Part of being both "here" and "there" consists in seeing things in person (i.e. in the light of one's "here") that one knows are "there" and thus Urry (1990:12) notes the significance to tourists of the unfamiliar juxtaposed to the familiar, such as home amenities in a peer-to-peer type of accommodation, or everyday activities carried out in an unfamiliar manner or situation. The experience thus seems to depend upon juxtaposing oneself and hence one's "clump of native soil" alongside what is being visited. This appears to answer a deep human need for self-identity, perhaps forming the basis of the transformation that tourists hope to find through their travels (Graburn, 1989; Bruner, 1991; Suvantola, 2017).

Place and space are also distinguished by the strategic or tactical approaches one takes to one's environment (De Certeau, 1984: 35-36). The peer-to-peer accommodation sector operates, beyond trading (Sigala, 2015), by occupying space, making it one's own "place", where one can bide one's time and make one's plans, and from which resources can be marshalled to accomplish one's ends. In general, tourists travelling from "here" where they own territory, by law or familiarity, to "there", become strangers in a land belonging to 
others, and are thereby transferred from a strategic to a tactical position. Removed from their strategic power base, they feel in the position of outwitting more powerful opponents, through ruses, in their own territory. Staying in someone's home, helps reduces this distance. This psychological distance represents a subjective experience in which an object or event is close or far in temporal dimension, spatial dimension, or social dimension (Liberman \& Trope, 1998). While several different kinds of psychological distance have received attention in research, social distance appears relevant for studying institutional versus peer-to-peer communities.

The current study contributes theoretically to the understanding of the social/personal dimension and its relationship with the home construct in online peer-to-peer reviews. In particular, whether consumer's home construct allows them to feel at a lower level of social distance, i.e., higher level of interaction between actors, which might prevent a negative review thanks to the activation of a vicarious experience in the shoes of the (non)reviewed.

\section{Empirical context}

This study uses the principles discussed above to mainly examine the way customers use their perceptions of "here" as they construct and interpret their experience and whether this reduces social distance leading to online review bias.

It explores an institutional and a peer-to-peer environment, characterised by different levels of social interactions. The empirical context is the accommodation realm. For the sake of comparability between environments, we consider just platforms involving monetary transaction.

We study whether reporting behaviour after having a bad experience differs in relation to social distance manifested in the notion of "home and away". In this case, "home" being Airbnb and "away" being traditional operators.

\subsection{Peer-to-peer accommodation networks}

In recent years, the phenomenon of sharing economy has emerged in tourism marketplaces (Guttentag, 2015) as a form a collaborative consumption. Sharing economies concept refers to the consumers possibility to temporarily access other's products and services (Bardhi \& Eckhardt, 2012) by paying for this experience. This tendency has been recently facilitated by the increasing connectivity of social network platforms helping peers' connections (Tussyadiah \& Pesonen, 2018). 
The rapid growth of sharing economies is driven by several factors, including societal, technologic and economic (Owyang, 2013), although collaborative consumption is driven by motivations that extend beyond the mere cost savings (Botsman \& Rogers, 2011) and have to do with a consumers' changing attitude towards consumption (Gansky, 2010). Interestingly, younger consumers (Gaskins, 2010; John, 2013) and consumers with higher income levels (Olson, 2013) are more likely to participate in collaborative consumption.

Within the hospitality industry, the most successful peer-to-peer platform is Airbnb (Gutiérrez et al., 2017), connecting hosts and guests across 190 countries and over 2 million listings. Since the advent of Airbnb has revolutionized the accommodation realm, several studies attempted to estimate its disruptive effects on the business (Guttentag, 2015) and its competition with the traditional accommodation (Zervas et al., 2017; Choi et al., 2015). Hospitality plays a critical role in peer-to-peer accommodation experience, although its concept differs from the professional hospitality typical of hotels (Brotherton, 1999). In peerto-peer accommodation systems, indeed, the host-guest direct interaction is predominant and personal experiences sharing drives travelers to connect with local communities (Guttentag, 2015).

\subsection{Peer-to-peer exchange relationships}

These environments encompass peer-to-peer platforms based on monetary transactions. In this case the social component is predominant and, thus a monetary transaction is present, people are mainly driven by social norms, given an even power position (Visconti, 2016). The degree of interaction goes from moderate, i.e., renting the whole listing, to very high, where the experience is the result of a high interaction between customer and provider, i.e., renting part of a house. The adopted case for this context is Airbnb.

\subsection{Traditional market exchange relationships}

These environments include business to customer (B2C) platforms, where consumers review traditional operators (e.g., Booking, TripAdvisor, Yelp), following a business-set rules.

In choosing a specific source to mirror these markets we focused on Booking.com, given its popularity and trustworthiness compared to similar competitors (Filieri, 2016).

\section{Research methodology}

The empirical approach consists of two different phases.

The first, exploratory in nature, compares quantitatively the average review scores of hotels and listings in Booking.com and Airbnb, respectively. 
The second phase investigates qualitatively through in-depth interviews whether and how the social/personal dimension driven by the construct of 'home' hinders the willingness to express bad experiences through online reviews.

\subsection{Methods}

\subsubsection{Quantitative exploratory analysis}

To provide a general picture of the possible bias in reporting negative experiences among traditional hotels and Airbnb accommodation, in November 2016 the study compared the average review scores of hotels in Booking.com and the average review scores of listings in Airbnb for the 6 most popular European destinations according to the global destination cities index (GDCI, 2015). This index ranks the travel destinations worldwide based on the overnight incoming visitor volume and expenditure (D'Acunto et al., 2019) offering a certain degree of variety in the sample. The reason of comparing traditional hotels (Booking.com) versus peer-to-peer platform (Airbnb) comes from the assumption that a home like environment associated with the construct of 'here' enables a lower social distance due to a higher personal interaction between the host and guest. This appears to influence the reporting behaviour of negative experiences (Liviatan et al., 2008; White, et al., 2011).

\section{INSERT TABLE 1 HERE}

As can be seen from Table 1, there is a consistent gap in the average review score in favor of Airbnb listings compared to Booking.com, with the former being around 20\% higher and presenting a left skewed distribution, by means of skewness normality test $(-0.6)$. Specifically, through a bootstrap estimation of the standard error at different levels of the distribution (Wilcox et al., 2014), we find that the proportion of negative ratings is higher in Airbnb (vs. Booking.com), $\mathrm{p}<0.01$.

This exploratory phase suggests us to qualitatively dig further in the direction of possible reviewing bias. Preliminary findings will be discussed in the related section.

\subsubsection{Qualitative Research}

Qualitative research was selected as an approach to some of the data collection in this study. This allowed participants to tell their stories and express their feelings without restriction, Figueroa-Domecq et al. (2015). The qualitative data was collected through a semi structured interview method and an interview guide with a list of topics was prepared. As the topic being researched has been sparingly documented (Grove \& Fisk, 1997) the interviews are used as a companion research method in mixed-method studies (Kolbe \& Burnett, 1991; 
Gremler, 2004). A flexible approach was taken to allow participants to lead discussions; this was found useful in such an exploratory study on a topic on which relatively little is known. According to Jones and Crompton (2013) semi-structured interviews are known for their flexibility and spontaneity. The interviews explore the customer (non) reporting behaviour following a negative service experience specifically in a peer to peer context.

\subsection{Sampling and process}

Purposive and convenience sampling was employed in order to select 'information rich' individuals (Devers \& Frankel, 2000: 264) and have a good understanding of participants' experiences. Participants were selected among hotel customers who are active online reviewers and have stayed at both Airbnb and traditional hotels while travelling for leisure. The sample of participants was chosen through the authors' professional and personal networks please see table 2 for the participant profiles. To avoid possible influences of the price level, we considered situations in both institutional and peer-to-peer context ranged between 60 and 80 euros. Data collection ended when saturation was reached at 35 interviews (Tracy, 2010).

\section{INSERT TABLE 2 HERE}

Ethical considerations were followed to ensure that participants were made aware of the aim of the research and were asked to provide their consent. Participants were also informed that they would be able to terminate the interview and withdraw at any time and without the need to give reasons. Participants' confidentiality was also promised and maintained.

Interviews were conducted over a period of 32 weeks with each one lasting from 45 to 60 minutes. Data was digitally recorded and transcribed by the authors. Conversations revolved around participants' feelings about their experience, staying at a hotel or an apartment within the sharing economy sector Airbnb. Their accounts of happiness and/or disappointments with the experiences were explored. Participants were also asked to elaborate on their online reporting behaviour in both situations and to shed light on the reasons behind not taking action in the case of negative experiences. Most importantly, interactions with the host or hotel staff were also explored to see if the notions of 'here' and 'there' and the social distance influenced participants' experiences and consequently their reporting behaviour.

\section{Data analysis}

A general analytic framework (Yin, 2013) was used to analyse and interpret the data. This analytic framework comprised three stages: (1) analysis of individual interviews and transcripts, (2) identification of common recurrent themes and (3) analysis of shared themes. 
Each transcript was analysed separately as a unit of analysis to understand both the experience of those individuals and to identify the emerging themes. The coding scheme was unrestricted, imaginative, and was not content specific (Miles \& Huberman, 1994). All three authors undertook coding of data independently in parallel to provide researcher triangulation (Denzin, 2012).

The second stage involved categorical aggregation and the search for emerging patterns. The third stage organised the data into more abstract units of information by building categories and patterns inductively so that meaning could be extracted and theory developed. The data were revisited to search for relationships between the shared themes and the different concepts that had emerged. Potential patterns and relationships within and between the shared themes and the core theme of "response-bias" were examined to determine how exactly they influenced the shared aspects of the informants "lived experience". For example, it was found that the intensity of interaction with the host affected reporting bias. Respondents who had a meaningful interaction with the host tended not to report their negative experiences or not to mention them in their review.

Reliability assessment was independently repeated by the three authors analysing a randomly chosen 5 questions per 10 interviews as a reliability check, which scored 79\%. The items on which there was no initial consent were discussed and agreed on.

\subsection{Findings}

\subsubsection{Preliminary exploratory findings}

The quantitative exploratory findings are consistent with the ones of Ert et al. (2016) and Zervas et al. (2017) regarding the distributions of ratings when comparing peer-to-peer accommodations with institutional ones (see Table 1). As a possible explanation, we propose that when guests experience the feeling at "home" condition (i.e. renting a room on Airbnb) they feel more reluctant to leave a bad review in case of negative experience. On the other hand, consumers travelling in traditional hotels (i.e. "away" condition) do not feel restrained in negatively reviewing when something goes wrong during their stay. On a large scale, this phenomenon may contribute in affecting such differences in the average ratings between Airbnb and Booking.com listings. Our argument is that personal experiences lead consumers to a more indulgent attitude toward service failure, refraining from providing negative reviews. However, there are at least three alternative explanations for these quantitative evidences. First, consumers might self-select into these two categories (institutional vs. peerto-peer) based on personal predisposition. Second, peer-to-peer platforms like Airbnb include different levels of social interaction. The most prominent difference is whether customers rent the whole listing or share spaces with the host (rent a room). These two groups of Airbnb 
customers have been also found to be substantially different (Lutz \& Newlands, 2018). Third, different average levels in the ratings across platforms might simply point at different quality levels, and not at reporting biases. In other words, average experiences in peer-to-peer platforms could simply be better than good experiences in institutional environments.

To control for these alternative explanations, i) we conduct a qualitative analysis with leisure travellers who have been both in Booking.com and in Airbnb, ii) we consider different levels of peer-to-peer involvement: renting of entire houses and renting of rooms and iii) we take the social distance and the construct of home and away as a theoretical framework to explore the underlying motives behind reporting bias in negative experiences especially in the peer-topeer context.

Given our aim of exploring the negative reporting behaviour of customers, our focus is on phenomenographic conceptions, that is, consumers' understandings of their lived negative experiences, and their attitudes towards leaving a feedback about it. The core themes emanating from interviews are i) the value of negative reviews during decision making, ii) consumers' reporting behaviour of experiences in a traditional institutional exchange context, iii) consumers' reporting behaviour of experiences in a peer-to-peer context and iv) characteristics of the biased reviews in the peer-to-peer context. A specific emphasis on nonreviewing behaviours was given during the interviews.

\subsubsection{The value of negative reviews in decision making}

The key starting point for understanding consumers' potential bias in reporting negative experiences is the understanding of the weight consumers place on negative reviews. The qualitative findings clearly unveil that participants highly value negative reviews in their decision-making process, considering them more informative and useful than positive ones. In all two contexts negative reviews are generally read first and considered more relevant; "I concentrate only on negative reviews, I always leave out the positive one, they never give any information" Andy; "Negative information is much more useful ... if someone writes negative things there must really have been a reason to do it" Mahmoud.

O'Connor (2010) stated that $60 \%$ of people checked consumer reviews before purchasing products or services online. Out of these, $80 \%$ of consumer decisions were influenced by the reviews. Also, (Öğüt \& Onur Taş, 2012) found that $84 \%$ of all hotel guests use online reviews to help them plan their holidays. Furthermore, Viglia et al. (2016) argue that hotel managers should strive to understand the effect of consumers' attitude to online reviews on their decision making and in turn hotel performance. 
There is no doubt that consumers pay more attention to negative reviews in order to find out about non-biased views on such an intangible service. This is in line with Yan \& Jiang's (2018) view about consumers' placing more weight on negative reviews. Sparks and Browning (2011) found that consumers look for early negative information first. They assert that positively framed reviews on the other hand, influence consumer's choice and increase consumer trust and intention for booking. Recognising the influence of online reviews, participants seem to avoid the reporting of their own negative experiences fearing potential harm to the provider. Viglia et al. (2016) argues that hotel managers should strive to understand the effect of consumers' attitude to online reviews on their decision making and in turn hotel performance.

The following sections explain more about the motives behind the non-reporting behaviour in both traditional institutional and peer to peer contexts and the influence of social interaction between the actors following a negative experience.

\subsubsection{Consumers' reporting behaviour of experiences in a traditional institutional exchange context}

It became apparent form the interviews that only 5 out of 35 participants opted not to leave a review after a negative experience in a hotel. Reasons for this ranged from not wishing to waste time or the triviality of the issue as put forward by Lan; "I found the issue not worth wasting time over". Furthermore, it is interesting to note that there was a sense of disengagement against the organisation prevailed among participants who chose not to leave negative feedback. Some felt that they were only 'a number' to the organisation due to the minimum interaction they had with the hotel staff and the lack of interest expressed in their stay. 'No one really talked to us much and no one was interested to ask us at check out how our experience was' Peter. "I felt like I was talking to myself", Hania. This feeling of alienation supports the notion of 'there' explored in the literature review for this research. The participants felt like strangers in a place belonging to others imposing some kind of a psychological distance on them (Liberman \& Trope, 1998). This distance affected their reporting behaviour and discouraged them from leaving a review altogether.

Alternatively, the majority of the respondents who encountered negative experiences engaged in negative online reporting. The motivation was partially to seek compensation from the hotel as part of a customer care recovery approach.

"I complained with Customer Care and they took care of the matter"; "I left a negative review, I had no pity, and when I returned they were very kind to me" shared by Morris and 
Sam respectively. By taking direct action and voicing their disappointment towards the organisation, the participants enact a problem coping strategy (Stephens \& Gwinner, 1998) obliging the organisation to acknowledge and solve the problem. When this happens, a forgiving attitude is elicited (Jin et al., 2019). Conversely, the lack of reporting leads to a lack of responsiveness in dealing with the failure of the service triggering negative reviews. Yang and Mattila (2012) emphasised that most dissatisfied customers do not complain, but rather express negative word-of-mouth or terminate their business relationship with the company.

Moreover, the findings don't report any evidence of felt sympathy towards members of the staff who appeared empathetic towards customers' negative experiences, as expressed in Sam's comment above. Staff empathy didn't prevent customers from voicing their dissatisfaction through their negative online reporting.

"The hotel was under refurbishment (which I didn't know of), I arrived with a friend who suffers from severe allergies. After we checked in, there was a strong smell from the new carpet (...). Within 5 minutes, my friend's allergy began acting up which led to us asking the receptionist if we could be moved. I immediately called the receptionist, as you would normally do, who tried everything she could. She was very distressed about not being able to help us. We understood her reasons but still left a horrid review". Gigi

It's interesting to note here that consumers were able to view staff members as separate from the company and therefore, were not sympathetic towards them. Consumers disengaged themselves from the company and in the same way they did the hotel staff. Reporting negative experiences was, in their mind, an act directed at the company and not at the staff. This perceived separation from the organisation is driven from the low level of interaction resulting in a greater sense of 'there' leading to a strategic and tactical approach to their environment (De Certeau, 1984). In other words, despite recognising the staff member's empathetic response and her justification for the lack of corrective action, the customer's behaviour was influenced by the formal and impersonal relationship with the staff member. This distance did not help against a negative review, where the element under attack becomes the institution as a whole, instead of a person: "I wanted to share the negative experience so that others know and avoid that hotel" Alex. The overall goal of writing a negative review is both to punish the hotel and to protect other future customers.

Furthermore, the construct 'there' adds to the distance and reduces the empathetic appraisal of the experience. The perceived social distance with the institution as something 'there' makes the low level of interaction seem normal and leads to customers feeling less empathetic to 
individuals working in the institution (Darke et al., 2016). This can be seen as a reason for the indifference in leaving a negative online review.

Interestingly, it was evident form the interviews that participants tend not to leave a review if their expectations were solely met. They left a positive review only in cases of extraordinary service, 'the breakfast is to die for, the service is top, they almost iron my underwear when I leave it on the bed, they are extremely clean that you don't want to leave a mess in the room, I don't know how to explain it, you feel in kind of awe' Fred. This finds echo in Hu et al. (2009) in that consumers who experienced moderate quality of service were less inclined to report their experiences. Viglia et al. (2016) corroborated that this under reporting bias affects the reliability of online reviews.

\subsubsection{Consumers' reporting behaviour of experiences in a peer-to-peer exchange context}

On the contrary, the interviews show that empathic vicarious experiences prevent guests to post a negative review in a peer-to-peer context. Undergoing negative experiences without the willingness to report them was evident whenever hosts and guests developed some kind of a bond. A bond where an emotional context based on elements such as feeling 'here', at home and a genuine concern for the other person's welfare was experienced. This is explained in Dalia's negative experience below:

"To get to the fourth floor there was a lift but to use it you needed to put 5 cents into a box. I didn't have them... I decided to exercise... The place was a dump! (...) and it was really pricy! ....I don't know how we stayed up until 1.00 am and she (Vera the host) told me how her Egyptian husband had left her with two kids as soon as he managed to get a residence permit. Now she was on her own without knowing where he ended up. I decided I would give her a good review despite everything. It almost felt I couldn't betray her".

The participant in the above example has chosen not to report her negative experience online to warn other potential customers, unlike in the case of hotels reported by Alex, as she felt high empathy for the host. This is only possible when the guest and the host overcome the social distance and engage in a self-disclosure and self-revelation process. This is enabled by the feeling of 'here' or home created by living in with the host and sharing life stories. The home environment also allowed for a degree of relax and cosiness which led the host to involve the guest with personal accounts of her life. The bond created as a result made for an authentic environment naturally encountered at the guest's actual home, consequently evading the reporting of any negative aspects of the experience to protect the host. 
Another participant went a step further feeling that he was obliged to leave a positive review regardless of the experience, 'I feel almost obliged especially if the host is very participatory, it seems wrong not to leave a good review', Sergio. Same view expressed by Sam 'in the case of Airbnb, you have a person who opens his home, so you feel obliged to leave a good review, there's a bond due to the fact that you have come to know the person'.

What is described is an unpredictable script, social in nature, where there is a genuine concern between the actors. Genuine interest between the actors lead to unexpected outcomes: "When I arrived home very late, the girl (the host), who had been studying all day, instead of going to bed as she had to sit an early exam the following day, stayed up to chat with me only to get to know me better" Anabella. The participant explained how friendliness and hospitality corroborate to create a personal bond between the two.

Furthermore, when the participant feels empathy towards the host who showed regret for the service failure, he or she tends refrain from leaving a negative review, as shared by Jerry: "He looked apologetic and regretful, and excused a lot. I was really touched by it".

In sum, being in an Airbnb was reported in the finding as being 'home away from home', a phrase often associated with hotels, however, the relatively new phenomenon of the sharing economy, with all what entails from sharing a part of one's self (own home) makes it seem more appropriate. 'They talked to us about their children, we felt included and this is the reason we stay at an Airbnb, George. When hosts and guests share a physical space (i.e. shared accommodation) a personal connection occurs. Such factors are key in placing the guest 'here' (at home) leading to a low social distance where the guest-host relationship is conducted within a context defined by those traditions of which each individual's life is a part (MacIntyre, 2003).

Conversely, a feeling of being 'away, leading to a high social distance still occurred in the context of peer to peer exchange when interactions with the host were superficial or kept to a minimum. In this case, participants did not seem to hesitate in reporting a negative experience despite any sympathy with the host's circumstances. This happens especially when the service offered by a host is perceived as impersonal (letting out a whole apartment and not meeting the owner upon arrival or leaving the key in an automated safe). A traditional hotel provision comes to mind. This is described in the examples below:

"The problem was the bathroom. We had booked the whole flat with two bathrooms but one was out of order. The owner arrived only after two days of complaining, probably because 
she had many apartments. She was old and very tired. I was sorry for her being so old and still needing to sort out "work" but this didn't prevent me to leave a negative review". Christine

Similarly, Fred, who reported his negative experience, stressed the fact that his was an impersonal one and unexpected in a peer to peer context: 'He (the host) was one with many apartments to rent out, he wasn't waiting for us at his place, he did not welcome us, instead we had a Russian guy arrive by a scooter with two envelopes with keys for two apartments asking us which one was for us'.

It is interesting to note that any similarity with a traditional hotel model, defying the notion of the shared economy, is immediately perceived by consumers as an impersonal experience contributing to the feeling of 'there' and increasing the social distance and. In this context the host is taking a transactional approach to business which was found by Osman et al. (2009) to focus more on high volume of sales and less on building a rapport with the consumer. The determinant of success in this case is the number of transactions, revenue and profitability. The notion of sharing a part of one's home, naturally sought after by Airbnb consumers, with all what entails from intimate social and cultural exchanges with feelings of authenticity, familiarity and spontaneity, is eradicated with any glimpse of a transactional model typically followed by traditional hotels (one with many apartments to rent out, Fred).

While the above examples took place in a peer to peer context, it echoed the offering of a traditional hotel where a formal exchange occurred preventing the guest to immerse themselves in the host's life and build a close bond. This bond appeared in the data to be the reason behind the non-reporting of negative experiences in this context.

It needs to be acknowledged however, that reporting bias can occur when participants are afraid of retaliatory outcome resulting from a negative feedback. For example, two interviewees chose not to report the negative experience confirming the importance of the aspects of reciprocity and retaliation (Bolton et al., 2013). Marcel, for example, not being sure of the consequences of his potential negative review decided not to give one; "I didn't leave a review because I intended to use the same account also to host." As stated by Pera et al. (2019), reciprocity is an important feature which may affect the reporting behaviour. Fabio also agreed 'it's a "do ut des" Airbnb. If I evaluate you well, you evaluate me well... It is a barter'. It can be argued that this fear of host retaliation contributes to the evident inflation of positive reviews in the peer to peer context. 


\subsubsection{Characteristics of the reviews in a peer-to-peer exchange context}

Alternatively, participants who reported positive experiences, their reviews were mainly host driven and emanated from a distinct social exchange: 'she welcomed us in a wonderful way, prepared us tea, it was delicious'. 'it was a home of an artist, she was extremely clean, very kind, once we arrived, she prepared us some Italian Bruschetta', Fabio. Same as Anna's experience, 'he (the host) ordered the objects in the room in a parallel way, he's like this, a really nice guy, he gave me a bottle of wine, and they were a wonderful couple'. In this case, the host personality enriches the experience and allows for a more authentic cultural exchange.

Furthermore, feeling of home, 'here, in the context of peer-to peer enables service recovery to go over and beyond what's expected from a traditional model of hospitality. In the case of George who lost his dog as a result of inadequate arrangement from the host to accommodate his family and pet, found their effort to help similar to those of close family members:

'the whole family was mobilised immediately, the grandfather asked me to look after his nephew and loaded my partner on the scooter and went around looking for it on the streets, the sister helped us make a Facebook post, her husband took us to the police station to report our dog missing, it was extra ordinary help, when we found our dog, the grandfather helped us build a gate in the garden to keep our dog from escaping again'.

George left a positive feedback about the host despite the distress caused as a result of losing his dog on their first day of arrival. It is evident that in the nature of the social encounter facilitated by a peer to peer context, enables a type of bond which can only be experienced at home among family members who group, in most cases, to extend a helping hand in times of trouble. This personal dimension was always present in positive reviews.

\section{Discussion and conclusion}

In the traditional accommodation realm, guests experience a feeling of alienation which supports the notion of 'away' or 'there' explored in the literature review for this research. The participants felt like strangers in a place belonging to others feeling a psychological distance (Liberman \& Trope, 1998). This distance affected their reporting behaviour discouraging them from leaving a review.

Moreover, staff empathy didn't prevent customers from voicing their dissatisfaction through their negative online reporting since consumers are able to view staff members as separate 
from the company. This perceived separation from the organisation is driven from the low level of interaction resulting in a greater sense of being 'away' leading to a strategic and tactical approach to their environment (De Certeau, 1984).

Within traditional hotels, the interaction takes place according to prescribed roles, and institutional scripts. The process is described as predictable in terms of behaviours and roles. The findings show how the traditional industry does not only rely on providing accommodations, food, and drinks, but also prescribed social interaction between staff and guests (Hochschild, 1983). If something goes wrong in intrinsic terms (characteristics of the rooms, etc.) they generally choose to write a negative review. This is exaggerated by the construct of 'away' where institutions are psychologically placed, increasing the social distance. The fact that traditional hotels are psychologically removed from 'here' or 'home' makes a negative review impersonal.

Conversely, in peer-to-peer context, despite a contractual and economic agreement between hosts and guests, conformity to social obligations, more than to economic ones, is present. Participants experience a low social distance as a consequence of a strong interaction between hosts and guests and a feeling of being 'home'. This feeling of 'home' makes for a feeling of social togetherness that crosses the boundaries of economic transactions and transcends both hosts' and guests' economical gains. The interaction is embedded in an unpredictable, informal, and open process and is the prerequisite of a potential bonding and connection where social distance plays a key role in explaining why dissatisfied consumers become lenient when providing a feedback. In the case of a negative experience they try not to harm the provider if a positive and fruitful relationship has developed.

To conclude, the current research is inspired by the significant disparity of consumer reviews between institutional and peer-to-peer platforms, with the latter being characterised almost by the absence of negative reviews. Such evidence occurs despite the fact that consumers weigh negative reviews higher than positive ones when making purchase decisions.

The research looked into the construct of 'here' and 'there' as a theoretical framework in an attempt to understand the reporting behaviour and bias in the case of peer-to peer context versus a traditional institutional context. This construct is helpful in unpacking the psychological innuendos leading to the decision to protect the host. It sheds light on the underlying motives behind the empathetic approach taken in the case of negative experiences. This attitude, while protective, appears to be unhelpful in informing potential customers and/ or alerting hosts to existing problems. The value of reputation systems is at risk when online 
feedback is overloaded with reporting bias. Therefore, the construct mentioned above helped to provide insights on reporting bias especially in the case of a negative experience in a peerto-peer context, which are apparently, disperse (Zervas et al., 2017). In the overall peer-topeer environment, there are mixed interests. Platforms are generally willing to collaborate to maximise the accuracy of their systems in order to avoid a loss of image. On this line, Airbnb changed its policy precisely to avoid retaliation and biased review (Ert et al., 2016). Service providers instead have no interest to reduce biases, monetising an empathic competitive advantage toward traditional operators.

Our quantitative research helped to identify the surge in average review scores in the peer-topeer context as opposed to traditional hotels. While this is useful, an investigation using qualitative interviewed allowed for an understanding of the underlying motives behind the non-reporting behaviour of negative experiences. Interview data indicated the strong presence of reporting bias based on the proportion of peer-to-peer participants who have not left a review out of the total number who have experienced poor service.

\subsection{Theoretical contributions}

This research contributes to the current body of knowledge with regards to reporting behaviour in the shared economy accommodation platforms (e.g. Pera et al., 2019; Ert et al., 2016; Zervas et al., 2015). The social distance appeared to have an influence on reporting bias (Liberman et al., 2007; Trope \& Liberman, 2010), affecting guests' perception of feeling at "home" when travelling in peer-to-peer accommodation, rather than "away" when traveling in hotels. Also, this study is the first to use the literature on 'here' and 'there' (Crouch et al., 2001; Rojek, 1997) to advance our understanding of the construct of 'home' and 'away' and its effect on social distance contributing further to the body of knowledge on consumer reporting behavior (Zervas et al., 2015; Ert et al., 2016; Pera et al., 2019). The dimension of helpfulness of reviews is also an emerging contribution of this research. Consumers who experienced poor service in hotels, a business environment, offered realistic reviews with the intention to protect future guests and/or seek a corrective action. Alternatively, consumers who shared someone's home felt a low social distance with the host and developed a special bond. This bond stemmed from being 'home' and taking a social responsibility to protect members of the household, hence, not reporting a negative experience or reporting positive aspects of the experience masking reality in the process. In this case the usefulness of the review is questioned. It can be argued that perception of 'home' decreases the social distance which impacts the accuracy of the reviews. When consumers feel at 'home' in an informal, peer-to-peer context allowing a bond to develop with the host, reporting bias occurs. Similarly, consumers experiencing a highly personalised service in a hotel, tend to only report 
overly positive experiences. On the contrary, feeling 'away' or detached from the organisation, allows for more realistic reviews.

Our theoretical contribution is shown in figure one.

INSERT FIGURE 1 HERE

\subsection{Managerial Implications}

From a managerial standpoint this research offers three clear implications and actionable levers for managers. First, improving the understanding of how reporting attitudes are formed helps traditional and peer to peer platforms alike in managing consumer experiences. Second, emphasizing the strong role of social distance, institutional operators are encouraged to expand on personal elements, favouring personalisation of service and human connections (Pera et al., 2019), in order to generate the "home" feeling in guests. Third, exploring the reasons behind the severed bias in peer-to-peer cases where consumers share spaces with the host, would serve as an informative cue for new potential customers and the way they perceive online reviews. Despite the common perception that reviews have empowered consumers, (Labrecque et al., 2013) they are not always reliable. Therefore, there is a need for consumers to be transparent and voice their experiences to provide true and helpful information for others, the notion upon which the sharing economy lies.

\subsection{Limitations and Future research}

The study is not without limitations. Our approach aimed to provide a perspective about a topic that is largely debated offering a new theoretical angle. However, looking at causal relationships by an experimental design would allow to test how the actual guests' feeling at "home" or "away" affect their reporting behavior of negative experiences. Moreover, an experimental approach allowed us to overcome the retrospective approach inherent in the qualitative study, which represents a second limitation due to potential reinterpretation and memory lapses (Johnston, 1995). Also, despite that this study considers the six most popular European destinations, cultural differences across countries and reviewers' profile may be present, affecting the results. Future studies should look at this point, as well as considering hotels' level (e.g. stars) and classifications (e.g. chain/no chain, brands). 


\section{References}

Bardhi, F., \& Eckhardt, G. M. (2012). Access-based consumption: The case of car sharing. Journal of consumer research, 39(4), 881-898.

Bærenholdt, J. O., Haldrup, M., \& Urry, J. (2017). Performing tourist places. Routledge.

Bolton, G., Greiner, B., \& Ockenfels, A. (2013). Engineering trust: reciprocity in the production of reputation information. Management science, 59(2), 265-285.

Botsman, R., \& Rogers, R. (2011). What's mine is yours: how collaborative consumption is changing the way we live (Vol. 5). London: Collins.

Bridges, J., \& Vásquez, C. (2018). If nearly all Airbnb reviews are positive, does that make them meaningless?. Current Issues in Tourism, 21(18), 2057-2075.

Brotherton, B. (1999). Towards a definitive view of the nature of hospitality and hospitality management. International Journal of Contemporary Hospitality Management, 11(4), 165173.

Bruner, E. M. (1991). Transformation of self in tourism. Annals of tourism Research, 18(2), 238-250.

Cansoy, M., \& Schor, J. (2016). Who gets to share in the "Sharing Economy": Understanding the patterns of participation and exchange in Airbnb. Unpublished Paper, Boston College.

Caruana, A., \& Ewing, M. T. (2010). How corporate reputation, quality, and value influence online loyalty. Journal of Business Research, 63(9-10), 1103-1110.

Choi, K. H., Jung, J. H., Ryu, S. Y., Kim, S. D., \& Yoon, S. M. (2015). The relationship between Airbnb and the hotel revenue: in the case of Korea. Indian Journal of Science and Technology, 8(26), 1-8.

Crouch, D. (2010). Flirting with space: thinking landscape relationally. Cultural Geographies, 17(1), 5-18. https://doi.org/10.1177/1474474009349996

Crouch, D., Aronsson, L., \& Wahlström, L. (2001). Tourist encounters. Tourist studies, 1(3), 253-270.

Crouch, D., \& Desforges, L. (2003). The sensuous in the tourist encounter: Introduction: The power of the body in tourist studies. Tourist studies, 3(1), 5-22. 
D’Acunto, D., Tuan, A., Dalli, D., Viglia, G., Okumus, F. (2019). Do consumers care about CSR in their online reviews? An empirical analysis. International Journal of Hospitality Management, https://doi.org/10.1016/j.ijhm.2019.102342

Darke, P. R., Brady, M. K., Benedicktus, R. L., \& Wilson, A. E. (2016). Feeling close from afar: The role of psychological distance in offsetting distrust in unfamiliar online retailers. Journal of Retailing, 92(3), 287-299.

De Certeau, M. (1984), The practice of everyday life, University of California press.

Denzin, N. K. (2012). Triangulation 2.0. Journal of mixed methods research, 6(2), 80-88.

Devers, K. J., \& Frankel, R. M. (2000). Study design in qualitative research--2: Sampling and data collection strategies. Education for health, 13(2), 263.

Dovidio, J. F., Gaertner, S. L., Validzic, A., Matoka, K., Johnson, B., \& Frazier, S. (1997). Extending the benefits of recategorization: Evaluations, self-disclosure, and helping. Journal of Experimental Social Psychology, 33(4), 401-420.

Entrikin, J. N. (1991). The betweenness of place. In The Betweenness of Place (pp. 6-26). Palgrave, London.

Ert, E., Fleischer, A., Magen, N. (2016) Trust and reputation in the sharing economy: The role of personal photos in Airbnb. Tourism Management 55, 62-73.

Feng, S., Xing, L., Gogar, A., \& Choi, Y. (2012, May). Distributional footprints of deceptive product reviews. In Sixth International AAAI Conference on Weblogs and Social Media.

Figueroa-Domecq, C., Pritchard, A., Segovia-Pérez, M., Morgan, N., \& Villacé-Molinero, T. (2015). Tourism gender research: A critical accounting. Annals of Tourism Research, 52, 87103.

Filieri, R. (2016). What makes an online consumer review trustworthy? Annals of Tourism Research, 58, 46-64.

Fradkin, A., Grewal, E., Holtz, D., \& Pearson, M. (2015, June). Bias and reciprocity in online reviews: Evidence from field experiments on airbnb. In Proceedings of the Sixteenth ACM Conference on Economics and Computation (pp. 641-641). ACM.

Fradkin, A., Grewal, E., \& Holtz, D. (2018). The determinants of online review informativeness: Evidence from field experiments on Airbnb. 
Gansky, L. (2010). The mesh: Why the future of business is sharing. Penguin.

Gaskins, K. (2010). The new sharing economy: Latitude. Retrieved June 15, 2019, from http://latdsurvey.net/pdf/Sharing.pdf

GDCI. (2015). Master card global worldwide insights. Retrieved from https://newsroom.mastercard.com/wpcontent/uploads/2015/07/Mastercard GDCI 2015 Lette r_Final_70814.pdf.

Graburn, N. (1989). Tourism: The Sacred Journey. Hosts and Guests: The Anthropology of Tourism. Edited by Valene Smith.

Gremler, D. D. (2004). The critical incident technique in service research. Journal of service research, 7(1), 65-89.

Grove, S. J., \& Fisk, R. P. (1997). The impact of other customers on service experiences: a critical incident examination of "getting along". Journal of retailing, 73(1), 63-85.

Gutiérrez, J., García-Palomares, J. C., Romanillos, G., \& Salas-Olmedo, M. H. (2017). The eruption of Airbnb in tourist cities: Comparing spatial patterns of hotels and peer-to-peer accommodation in Barcelona. Tourism Management, 62, 278-291.

Guttentag, D. (2015). Airbnb: disruptive innovation and the rise of an informal tourism accommodation sector. Current issues in Tourism, 18(12), 1192-1217.

Han, H. J., Mankad, S., Gavirneni, N., \& Verma, R. (2016). What guests really think of your hotel: Text analytics of online customer reviews.

Hennig, C. (2002). Tourism: Enacting modern myths. The tourist as a metaphor of the social world, 169-187.

Hochschild, A. R. (1983). The managed heart. Berkeley.

Hoffman, E., McCabe, K., \& Smith, V. L. (1996). Social distance and other-regarding behavior in dictator games. The American Economic Review, 86(3), 653-660.

Hu, H. H., Kandampully, J., \& Juwaheer, T. D. (2009). Relationships and impacts of service quality, perceived value, customer satisfaction, and image: an empirical study. The service industries journal, 29(2), 111-125. 
Hu, N., Zhang, J., \& Pavlou, P. A. (2009). Overcoming the J-shaped distribution of product reviews. Communications of the ACM, 52(10), 144-147.

Ikkala, T., \& Lampinen, A. (2015, February). Monetizing network hospitality: Hospitality and sociability in the context of Airbnb. In Proceedings of the 18th ACM conference on computer supported cooperative work \& social computing (pp. 1033-1044). ACM.

Jin, D., Nicely, A., Fan, A., \& Adler, H. (2019). Joint effect of service recovery types and times on customer satisfaction in lodging. Journal of Hospitality and Tourism Management, $38,149-158$.

John, N. A. (2013). The social logics of sharing. The Communication Review, 16(3), 113-131.

Johns, N., \& Clarke, V. (2001). Mythological analysis of boating tourism. Annals of Tourism Research, 28(2), 334-359.

Johnston, R. (1995). The determinants of service quality: satisfiers and dissatisfiers. International journal of service industry management, 6(5), 53-71.

Jones, G., \& Crompton, R. (2013). Researching white collar organizations: why sociologists should not stop doing case studies. In Doing Research in Organizations (RLE: Organizations) (pp. 78-91). Routledge.

Jurafsky, D. (2014). The language of food: A linguist reads the menu. WW Norton \& Company.

Kolbe, R. H., \& Burnett, M. S. (1991). Content-analysis research: An examination of applications with directives for improving research reliability and objectivity. Journal of consumer research, 18(2), 243-250.

Labrecque, L. I., vor dem Esche, J., Mathwick, C., Novak, T. P., \& Hofacker, C. F. (2013). Consumer power: Evolution in the digital age. Journal of Interactive Marketing, 27(4), 257269.

Laing, J. H., \& Crouch, G. I. (2009). Myth, adventure and fantasy at the frontier: Metaphors and imagery behind an extraordinary travel experience. International Journal of Tourism Research, 11(2), 127-141.

Liberman, N., \& Trope, Y. (1998). The role of feasibility and desirability considerations in near and distant future decisions: A test of temporal construal theory. Journal of personality and social psychology, 75(1), 5 . 
Liberman, N., \& Trope, Y. (2008). The psychology of transcending the here and now. Science, 322(5905), 1201-1205.

Liberman, N., Trope, Y., \& Stephan, E. (2007). Psychological distance. Social psychology: Handbook of basic principles, 2, 353-383.

Liviatan, I., Trope, Y., \& Liberman, N. (2008). Interpersonal similarity as a social distance dimension: Implications for perception of others' actions. Journal of experimental social psychology, 44(5), 1256-1269.

Lutz, C., \& Newlands, G. (2018). Consumer segmentation within the sharing economy: The case of Airbnb. Journal of Business Research, 88, 187-196.

MacIntyre, A. (2003). The virtues, the unity of a human life, and the concept of a tradition, In L. Cahoone (Ed.) From Modernism to Postmodernism: An anthology. Oxford UK: Blackwell. pp. 550-563.

Martin, D. (2010). Uncovering unconscious memories and myths for understanding international tourism behaviour, Journal of Business Research 63(4): 372-383.

Meinecke, F. (2015). Cosmopolitanism and the National State, Princeton Legacy Library.

Miles, M. B., \& Huberman, A. M. (1994). Qualitative data analysis: An expanded sourcebook. Sage.

Nadler, J. (1999). Distributing adventitious resources: The effects of relationship and grouping. Social Justice Research, 12(2), 131-147.

O'connor, P. (2010). Managing a hotel's image on TripAdvisor. Journal of Hospitality Marketing \& Management, 19(7), 754-772.

Oakes, T. (2005). Tourism and modernity in China. Routledge.

Öğüt, H., \& Onur Taş, B. K. (2012). The influence of internet customer reviews on the online sales and prices in hotel industry. The Service Industries Journal, 32(2), 197-214.

Olson, K. (2013). National study quantifies reality of the "Sharing Economy" movement. Retrieved March 16, 2015, from http://www.campbell-mithun.com/678 national-studyquantifies-realityof- the-sharing-economy-movement 
Osman, H., Hemmington, N., \& Bowie, D. (2009). A transactional approach to customer loyalty in the hotel industry. International Journal of Contemporary Hospitality Management, 21(3), 239-250.

Owyang, J. (2013). The collaborative economy: Products, services and market relationships have changed as sharing startups impact business models. To avoid disruption, companies must adopt the collaborative economy value chain. Altimeter. Retrieved July 02, 2019, from http://www.slideshare.net/Altimeter/the-collaborative-economy

Pera, R., Viglia, G., Grazzini, L., \& Dalli, D. (2019). When empathy prevents negative reviewing behavior. Annals of Tourism Research.

Priporas, C. V., Stylos, N., Rahimi, R., \& Vedanthachari, L. N. (2017). Unraveling the diverse nature of service quality in a sharing economy: A social exchange theory perspective of Airbnb accommodation. International Journal of Contemporary Hospitality Management, 29(9), 2279-2301.

Resnick, P., Zeckhauser, R., Swanson, J., K. Lockwood (2006). The Value of Reputation on eBay: A Controlled Experiment. Experimental Economics 9(2), 79-101.

Rojek, C. (1997). Indexing, dragging and the social construction of tourist sightsF, in C. Rojek and J. Urry (Eds.) Touring Cultures Transformations of Travel and Theory. London: Routledge: 52-74.

Selwyn, T. (1996). The tourist image: Myths and myth making in tourism. Wiley.

Sigala, M. (2015). From demand elasticity to market plasticity: A market approach for developing revenue management strategies in tourism. Journal of Travel and Tourism Marketing, 32(7), 812-834.

Sparks, B. A., \& Browning, V. (2011). The impact of online reviews on hotel booking intentions and perception of trust. Tourism management, 32(6), 1310-1323.

Stephan, E., Liberman, N., \& Trope, Y. (2010). Politeness and psychological distance: A construal level perspective. Journal of personality and social psychology, 98(2), 268.

Steiner, C. J., \& Reisinger, Y. (2006). Understanding existential authenticity. Annals of Tourism Research, 33(2), 299-318. 
Stephens, N., \& Gwinner, K. P. (1998). Why don't some people complain? A cognitiveemotive process model of consumer complaint behavior. Journal of the Academy of Marketing science, 26(3), 172-189.

Sun, T., Youn, S., Wu, G., \& Kuntaraporn, M. (2006). Online word-of-mouth (or mouse): An exploration of its antecedents and consequences. Journal of Computer-Mediated Communication, 11(4), 1104-1127.

Suvantola, J. (2017). Tourist's experience of place. Routledge.

Tracy, S. J. (2010). Qualitative quality: Eight "big-tent" criteria for excellent qualitative research. Qualitative inquiry, 16(10), 837-851.

Trope, Y., \& Liberman, N. (2010). Construal-level theory of psychological distance. Psychological review, 117(2), 440.

Tussyadiah, I. P., \& Pesonen, J. (2018). Drivers and barriers of peer-to-peer accommodation stay-an exploratory study with American and Finnish travellers. Current Issues in Tourism, 21(6), 703-720.

Urry, J. (1990). Theconsumption'of tourism. Sociology, 24(1), 23-35.

Urry, J., \& Larsen, J. (2011). The tourist gaze 3.0. Sage.

Viglia, G., Minazzi, R., \& Buhalis, D. (2016). The influence of e-word-of-mouth on hotel occupancy rate. International Journal of Contemporary Hospitality Management, 28(9), 2035-2051.

Visconti, L. M. (2016). A conversational approach to consumer vulnerability: performativity, representations, and storytelling. Journal of Marketing Management, 32(3-4), 371-385.

Wang, N. (1999). Rethinking authenticity in tourism experience. Annals of tourism research, 26(2), 349-370.

Wang, Z. (2010). Anonymity, social image, and the competition for volunteers: a case study of the online market for reviews. The BE Journal of Economic Analysis \& Policy, 10(1).

White, K., MacDonnell, R., \& Dahl, D. W. (2011). It's the mind-set that matters: The role of construal level and message framing in influencing consumer efficacy and conservation behaviors. Journal of Marketing Research, 48(3), 472-485. 
Wilcox, R. R., Erceg-Hurn, D. M., Clark, F., \& Carlson, M. (2014). Comparing two independent groups via the lower and upper quantiles. Journal of Statistical Computation and Simulation, 84(7), 1543-1551.

Willis, C., Ladkin, A., Jain, J., \& Clayton, W. (2017). Present whilst absent: Home and the business tourist gaze. Annals of Tourism Research, 63, 48-59.

Yan, X., \& Jiang, P. (2018). Effect of the dynamics of human behavior on the competitive spreading of information. Computers in Human Behavior, 89, 1-7.

Yang, W., \& Mattila, A. S. (2012). The role of tie strength on consumer dissatisfaction responses. International Journal of Hospitality Management, 31(2), 399-404.

Yannopoulou, N., Moufahim, M., \& Bian, X. (2013). User-generated brands and social media: Couchsurfing and AirBnb. Contemporary Management Research, 9(1).

Yin, R. K. (2013). Validity and generalization in future case study evaluations. Evaluation, 19(3), 321-332.

Zervas, G., Proserpio, D., \& Byers, J. (2015). A first look at online reputation on Airbnb, where every stay is above average. Where Every Stay is Above Average (January 28, 2015).

Zervas, G., Proserpio, D., \& Byers, J. W. (2017). The rise of the sharing economy: Estimating the impact of Airbnb on the hotel industry. Journal of marketing research, 54(5), 687-705. 
Table 1. Average review score for hotels in Booking.com and listings on Airbnb

\begin{tabular}{lllll}
\hline & \multicolumn{3}{c}{ Booking.com } & Airbnb \\
\hline \multirow{2}{*}{ City } & $\begin{array}{l}\text { Average } \\
\text { Score (SD) }\end{array}$ & Numerosity & $\begin{array}{l}\text { Average } \\
\text { Score (SD) }\end{array}$ & Numerosity \\
\hline Amsterdam & $7.42(0.67)$ & 357 & $9.03(0.31)$ & 442 \\
Barcelona & $7.53(0.54)$ & 397 & $8.98(0.32)$ & 687 \\
Istanbul & $6.97(0.69)$ & 395 & $8.92(0.34)$ & 259 \\
London & $7.11(0.70)$ & 777 & $9.12(0.31)$ & 912 \\
Paris & $7.23(0.64)$ & 1187 & $8.97(0.34)$ & 893 \\
Rome & $7.50(0.65)$ & 853 & $9.07(0.29)$ & 523 \\
\hline
\end{tabular}

Table 2. Sample profile

\begin{tabular}{|c|c|c|c|c|c|c|c|c|c|c|c|c|c|}
\hline \multicolumn{14}{|c|}{ Sample profile: Last 5 years visits and reviews } \\
\hline Pseudonym & Age & Gender & Profession & $\begin{array}{l}\mathrm{n}^{0} \text { of } \\
\text { visit } \\
\text { Airbnb }\end{array}$ & $\begin{array}{l}\mathrm{n}^{\circ} \text { of } \\
\text { reviews } \\
\text { left on } \\
\text { Airbnb* }\end{array}$ & $\%$ & $\begin{array}{l}{ }^{*} \text { of } \\
\text { which } \\
\text { negative }\end{array}$ & $\%$ & $\begin{array}{l}\mathrm{n}^{\circ} \text { of } \\
\text { visit } \\
\text { Hotels }\end{array}$ & $\begin{array}{l}\mathrm{n}^{\circ} \text { of } \\
\text { Hotel } \\
\text { reviews } \\
\text { left** }\end{array}$ & $\%$ & $\begin{array}{l}{ }^{* *} \text { of } \\
\text { which } \\
\text { negative }\end{array}$ & $\%$ \\
\hline Fred & 42 & Male & Physicist & 10 & 8 & $80 \%$ & 0 & $0 \%$ & 40 & 40 & $100 \%$ & 3 & $8 \%$ \\
\hline Sam & 35 & Male & $\begin{array}{l}\text { Strategic } \\
\text { Consultant }\end{array}$ & 5 & 4 & $80 \%$ & 0 & $0 \%$ & 20 & 18 & $90 \%$ & 4 & $22 \%$ \\
\hline Sara & 39 & Female & Researcher & 6 & 4 & $67 \%$ & 1 & $25 \%$ & 25 & 24 & $96 \%$ & 2 & $8 \%$ \\
\hline Sivlia & 35 & Female & Doctor & 3 & 0 & $0 \%$ & 0 & $0 \%$ & 10 & 10 & $100 \%$ & 2 & $20 \%$ \\
\hline Kerry & 26 & Female & Professional & 8 & 6 & $75 \%$ & 1 & $17 \%$ & 28 & 24 & $86 \%$ & 6 & $25 \%$ \\
\hline Alfred & 28 & Male & Engineer & 13 & 9 & $69 \%$ & 2 & $22 \%$ & 46 & 36 & $79 \%$ & 8 & $22 \%$ \\
\hline John & 36 & Male & Teacher & 5 & 4 & $80 \%$ & 0 & $0 \%$ & 18 & 16 & $91 \%$ & 5 & $31 \%$ \\
\hline Andy & 35 & Male & $\begin{array}{l}\text { Computer } \\
\text { Engineer }\end{array}$ & 6 & 5 & $83 \%$ & 1 & $20 \%$ & 21 & 20 & $95 \%$ & 5 & $25 \%$ \\
\hline Veronica & 32 & Female & House wife & 5 & 3 & $60 \%$ & 0 & $0 \%$ & 18 & 15 & $86 \%$ & 4 & $27 \%$ \\
\hline Paula & 35 & Female & Pharmacist & 9 & 6 & $67 \%$ & 0 & $0 \%$ & 32 & 28 & $89 \%$ & 6 & $21 \%$ \\
\hline Yara & 23 & Female & House wife & 4 & 3 & $75 \%$ & 1 & $33 \%$ & 14 & 12 & $86 \%$ & 4 & $33 \%$ \\
\hline Han & 25 & Male & Builder & 3 & 2 & $67 \%$ & 0 & $0 \%$ & 11 & 11 & $100 \%$ & 4 & $36 \%$ \\
\hline Lan Dan & 23 & Female & Shop assistant & 10 & 7 & $70 \%$ & 1 & $14 \%$ & 35 & 30 & $86 \%$ & 9 & $30 \%$ \\
\hline Laila & 35 & Female & $\begin{array}{l}\text { Front office } \\
\text { employee }\end{array}$ & 8 & 6 & $75 \%$ & 1 & $17 \%$ & 28 & 24 & $86 \%$ & 6 & $25 \%$ \\
\hline Ming & 25 & Female & journalist & 25 & 21 & $84 \%$ & 2 & $10 \%$ & 88 & 80 & $91 \%$ & 21 & $26 \%$ \\
\hline Hania & 24 & Female & Teacher & 11 & 9 & $82 \%$ & 1 & $11 \%$ & 39 & 36 & $94 \%$ & 8 & $22 \%$ \\
\hline Mahmoud & 47 & Male & Personal Trainer & 8 & 6 & $75 \%$ & 1 & $17 \%$ & 28 & 24 & $86 \%$ & 6 & $25 \%$ \\
\hline Gigi & 44 & Male & $\begin{array}{l}\text { Freelance } \\
\text { journalist }\end{array}$ & 30 & 18 & $60 \%$ & 1 & $6 \%$ & 105 & 72 & $69 \%$ & 19 & $26 \%$ \\
\hline Morris & 42 & Male & Tree surgeon & 6 & 5 & $83 \%$ & 0 & $0 \%$ & 21 & 20 & $95 \%$ & 3 & $15 \%$ \\
\hline
\end{tabular}




\begin{tabular}{|c|c|c|c|c|c|c|c|c|c|c|c|c|c|}
\hline Alex & 27 & Male & IT technician & 5 & 3 & $60 \%$ & 1 & $33 \%$ & 18 & 15 & $86 \%$ & 3 & $20 \%$ \\
\hline Michael & 26 & Male & Physicist & 8 & 5 & $63 \%$ & 1 & $20 \%$ & 28 & 23 & $82 \%$ & 6 & $26 \%$ \\
\hline Marcel & 28 & Male & $\begin{array}{l}\text { Computer } \\
\text { Scientist }\end{array}$ & 12 & 8 & $67 \%$ & 2 & $25 \%$ & 42 & 35 & $83 \%$ & 15 & $43 \%$ \\
\hline Erric & 33 & Male & Sociologist & 14 & 7 & $50 \%$ & 1 & $14 \%$ & 49 & 40 & $82 \%$ & 12 & $30 \%$ \\
\hline Cristine & 33 & Female & Psychiatrist & 6 & 4 & $67 \%$ & 0 & $0 \%$ & 21 & 20 & $95 \%$ & 8 & $40 \%$ \\
\hline Donna & 35 & Female & Doctor & 5 & 3 & $60 \%$ & 0 & $0 \%$ & 18 & 16 & $91 \%$ & 5 & $31 \%$ \\
\hline Dalia & 51 & Female & Shop assistant & 6 & 5 & $83 \%$ & 1 & $20 \%$ & 21 & 20 & $95 \%$ & 5 & $25 \%$ \\
\hline Matt & 50 & Male & Shop manager & 8 & 5 & $63 \%$ & 0 & $0 \%$ & 28 & 25 & $89 \%$ & 10 & $40 \%$ \\
\hline Mario & 47 & Male & teacher & 12 & 7 & $58 \%$ & 1 & $14 \%$ & 42 & 34 & $81 \%$ & 8 & $24 \%$ \\
\hline $\mathrm{Ed}$ & 55 & Male & Scientist & 10 & 6 & $60 \%$ & 1 & $17 \%$ & 35 & 30 & $86 \%$ & 6 & $20 \%$ \\
\hline Veronica & 56 & Female & Head teacher & 9 & 5 & $56 \%$ & 1 & $20 \%$ & 32 & 27 & $86 \%$ & 8 & $30 \%$ \\
\hline Anabella & 32 & Female & Hair dresser & 6 & 5 & $83 \%$ & 0 & $0 \%$ & 21 & 20 & $95 \%$ & 4 & $20 \%$ \\
\hline Gerry & 49 & Male & Gardener & 3 & 0 & $0 \%$ & 0 & $0 \%$ & 11 & 11 & $100 \%$ & 3 & $27 \%$ \\
\hline George & 38 & Male & Professional & 18 & 10 & $56 \%$ & 1 & $10 \%$ & 63 & 45 & $71 \%$ & 4 & $9 \%$ \\
\hline TOTAL & & & & 9.0 & 6.1 & $67.4 \%$ & 0.7 & $11.0 \%$ & 31.9 & 27.3 & $88.7 \%$ & 6.7 & $25.3 \%$ \\
\hline
\end{tabular}


Figure1. Theoretical contributions

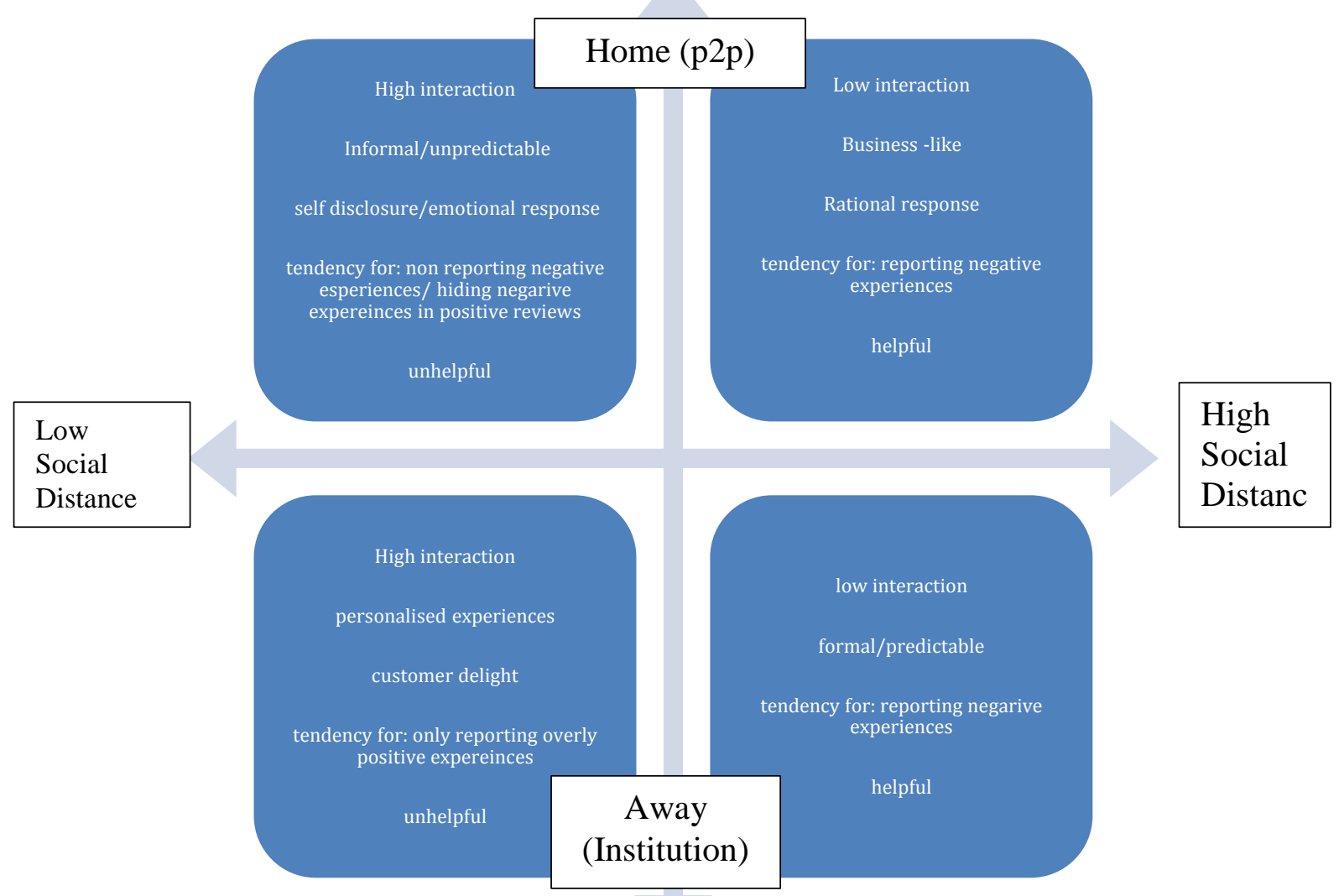

